\title{
Disseminated Cutaneous Leishmaniasis in Colombia: Report of 27 Cases
}

\author{
Iván D. Vélez Alejandra Jiménez Daniel Vásquez Sara M. Robledo \\ PECET, Medical Research Institute, School of Medicine, University of Antioquia UdeA, \\ Medellín, Colombia
}

\section{Key Words}

Disseminated leishmaniasis · Diffuse cutaneous leishmaniasis · Localized cutaneous leishmaniasis · Post-kala-azar dermal leishmaniasis

\begin{abstract}
Disseminated leishmaniasis (DL) is a poorly described disease that is frequently misdiagnosed as other clinical manifestations of cutaneous leishmaniasis $(C L)$ such as diffuse $C L$ or postkala-azar dermal leishmaniasis. Twenty-seven cases of DL diagnosed between 1997 and 2015 are described. A higher prevalence was observed in men (mean age 32 years). The number of lesions per patient ranged from 12 to 294, distributed mainly in the upper extremities, face and trunk. The lesions were mostly plaques or nodules. Seven patients had nasal mucous damage, $74 \%$ of the patients were of mixed race, $92 \%$ lived in northwestern Colombia, and Leishmania (Viannia) panamensis was identified as the causative agent in $58 \%$ of cases. Eighteen patients recovered with pentavalent antimonial. The importance of distinguishing $\mathrm{DL}$ from those other clinical presentations is based on the fact that disseminated, diffuse and post-kala-azar $\mathrm{CL}$ are very different in etiology, clinical manifestations and response to treatment and prognosis.

(c) 2015 The Author(s)

Published by S. Karger AG, Basel
\end{abstract}

\section{Introduction}

Cutaneous leishmaniasis (CL) is an infectious disease caused by the Leishmania parasite that is transmitted through the bites of phlebotominae sand flies. CL is characterized by broad clinical polymorphism varying from localized to diffuse and disseminated lesions. Localized CL (LCL) is the most prevalent clinical manifestation worldwide, characterized by 
the appearance of a skin lesion at the vector sting site. The lesion occurs after reproduction of the parasites into the dermis, which generates a granuloma. The granuloma is initially manifested as small papule that progressively increases in size to form a rounded nodule. As a consequence of the parasite virulence and host immune response, the nodules show necrosis in the center and become ulcers characterized by a round form, with high and clear borders, an indurated base and granular background, painless and with a scab firmly attached to the base. Overinfection with bacteria or fungi, often caused by empirical treatments, produces purulent and painful ulcers. Characteristic scars with hyper- or hypochromic edges, commonly called 'onion bulb scars', appear after treatment. Nodular lesions sometimes become scaly epidermal plaques or warty lesions [1]. In some patients, the parasite may spread via lymph and blood to the skin of different anatomical regions, particularly the face, chest and upper limbs, where the parasite reproduces widely and causes disseminated leishmaniasis (DL) or diffuse cutaneous leishmaniasis (DCL). Although these two clinical forms can be clearly differentiated (see table 1), some authors consider them as synonymous, which makes a meta-analysis of the literature review difficult.

Here, we report a series of DL patients attended at the PECET, University of Antioquia (Medellín, Colombia). A literature review focusing the attention on the available information to differentiate DL and DCL is also included.

\section{Case Presentation}

Between 1997 and 2015, 27 patients who were diagnosed with DL were treated. The patient characteristics are summarized in table 2. Twenty-two patients (85\%) were men; 20 patients $(77 \%)$ were of mixed race, 4 patients $(15 \%)$ were black, and 2 patients were indigenous; their age ranged from 4 to 61 years (mean 32 years). Twenty-five patients (96\%) were from the northwest of Colombia (Antioquia, Choco and Cordoba states), but only 2 patients came from the southeast of the country. Only 1 patient evidenced HIV coinfection. The other patients had a negative HIV serology. Parasite cultures were positive in 16 patients, while the remaining 11 cultures were negative. Leishmania (Viannia) panamensis was identified as the causative agent in 15 isolates; the last isolate was identified as Viannia subgenus, but no species was determined. This Leishmania species distribution is similar to that observed for patients with LCL from the northwestern Colombian region, where $70 \%$ of the strains circulating are L. (V.) panamensis and 30\% correspond to L. (V.) braziliensis, whereas in the southeastern region, $80 \%$ of the circulating species are $L$. (V.) braziliensis as identified by monoclonal antibody techniques and PCR-RFLP (unpublished data).

All patients met the diagnostic criteria of having 10 or more polymorphic lesions in at least 2 parts of the body surface. The number of lesions for each patient varied between 12 and 294 (21 patients with 100 lesions or less, 3 patients had more than 100 lesions and less than 200, and 4 patients had more than 200 lesions; table 3). The evolution time since the appearance of the first lesion to the spreading was more than 2 weeks. In most patients, the primary lesion was plaque, and the secondary lesions (disseminated) were nodules, papules and plaques, with different sizes but smaller than $2.0 \mathrm{~cm}$ in diameter. Only 1 patient had frank ulcers (fig. 1, fig. 2, fig. 3, fig. 4). Lesions were present mainly on the face, trunk and upper limbs. Seven patients (25\%) had nasal mucosal involvement consisting of ulcers, scabs or septal perforation indicating an important frequency of mucosal involvement.

The Montenegro skin test was positive in 18 of 21 patients (84\%) with an induration size that varied between 5 and $12 \mathrm{~mm}$ (average $6.8 \mathrm{~mm}$; table 2), suggesting no complete anergy of cellular immune response. Cell proliferation and $\mathrm{T}$ cell subpopulation in peripheral 
Vélez et al.: Disseminated Cutaneous Leishmaniasis in Colombia: Report of 27 Cases

blood samples were evaluated only in 4 patients who had absolute values of $\mathrm{T}$ cell and lymphoproliferative response within the reference values. However, the percentages of $\mathrm{T}$ cell $\mathrm{CD} 3+, \mathrm{CD} 4+$ and $\mathrm{CD} 3+\mathrm{CD} 4+$ subpopulations were below the reference values, whereas the percentage of naturally occurring regulatory $\mathrm{T}$ cells $(\mathrm{CD} 4+\mathrm{CD} 25+\mathrm{Foxp} 3+)$ were increased. Five of the 27 patients (19.3\%) had diabetes mellitus, obesity, vitiligo, HIV/AIDS and leukemia as baseline comorbidities, which could favor the spread of the parasite. In $92 \%$, their immunosuppressive condition was not identified, which could facilitate the spread of the parasite since most of patients were farmers from rural areas. Only 2 patients had a clinical condition-based immunosuppression (HIV and leukopenia).

Twenty-two patients were treated with intramuscular meglumine antimoniate at a dose of $20 \mathrm{mg} / \mathrm{kg} /$ day for 20 days (table 3). Treatment was extended to 28 days for those patients that had mucosal involvement. Nineteen of these 22 patients $(86.3 \%)$ were cured with a single treatment cycle of meglumine antimoniate, while 3 patients did fail. One of these 3 patients was cured with a second cycle with topical amphotericin B (Anfoleish ${ }^{\circledR}$ ) applied twice daily for 28 days, and the other 2 patients were cured with a second cycle with oral miltefosine at doses of $2-2.5 \mathrm{mg} / \mathrm{kg} /$ day for 28 days. One of these 2 patients had been treated before with amphotericin B deoxycholate $1 \mathrm{mg} / \mathrm{kg}$ daily only for 9 days because of renal toxicity. Among the remaining 7 patients, 2 of them were cured with 4 applications of intramuscular pentamidine at a dose of $3 \mathrm{mg} / \mathrm{kg} /$ day (table 3); another patient, who had 103 lesions, was cured after treatment with pentamidine combined with topical amphotericin B applied as before. Another patient was cured with miltefosine alone, and the last patient, who had HIV/AIDS coinfection, drug abuse, Kaposi's sarcoma, extrapulmonary tuberculosis, cryptococcal meningitis and poor adherence to antiretroviral therapy, was treated with liposomal amphotericin B combined with miltefosine; this patient showed partial clinical improvement but subsequent appearance of new skin lesions and extensive mucosal involvement.

\section{Discussion}

DL is characterized by an initial injury into the dermis followed by a high number of skin lesions ( $>10$ polymorphic lesions) in at least two parts of the body surface, with or without mucosal involvement [2,3]. DL has been described in Brazil, Venezuela, Guyana and Colombia, with a significant increase in the number of cases in highly endemic places as the Brazilian north, Colombo-Brazilian Amazon and Colombian northwest. This clinical manifestation is caused by Leishmania species of the subgenus Viannia, mainly L. (V.) panamensis, L. (V.) braziliensis and $L$. (V.) guayanensis. The higher incidence occurs in men, young adults and farmers [2]. Patients suffering DL describe the initial appearance of a single lesion (nodule or ulcerative plaque), presumably located in the vector bite site. Weeks or months later, as a consequence of parasite dissemination, polymorphic lesions (isolated or confluent), different in size and growth rate, appear in remote anatomic areas from the initial lesion that may cover the entire body surface, except armpits and inguinocrural region; lesions in the face may become disfiguring. Associated to the skin lesions, mucosal involvement or symptoms such as fever, chills and lymphadenopathy may occur $[2,4]$. Dissemination may occur after therapy with immunosuppressive drugs [5].

The pathogenesis of DL is not well established. However, partial inhibition of specific cellular immunity against the parasite has been demonstrated. A decrease in CD4+ T cells in peripheral blood with partial absence of $\mathrm{T}$ cell response to Leishmania antigen, evidenced by a mildly reactive ( 3 or $4 \mathrm{~mm}$ induration) or positive $(>5 \mathrm{~mm}$ ) Montenegro skin test, is ob- 
served [6]. A low production of the type Th1 cytokines IFN- $\gamma$, TNF- $\alpha$, IL-10 and IL-5, which favor the spread of the parasite, is also registered.

Histological examination of the lesions can reveal the presence of a granuloma composed of lymphocytic infiltrates with very few or no parasites $[4,7,8]$. A decrease in the percentage of $\mathrm{CD} 3+\mathrm{CD} 4+\mathrm{T}$ cells and an increase in the percentage of regulatory $\mathrm{T}$ cells could affect the immune response mediated by $\mathrm{T}$ cells because it has been shown that the regulatory $\mathrm{T}$ cells $\mathrm{CD} 4+\mathrm{CD} 25+\mathrm{Foxp} 3+$ (known as natural regulatory $\mathrm{T}$ cells) are potent suppressors of acquired immune response, as is the immune response mediated by T cells $[9,10]$. A decrease in the percentage of activated CD4+ T cells in the blood of patients may affect the cellular immune response associated with a decrease of the specific local cellular response against some Leishmania species.

The diagnosis of DL as well as other clinical forms of CL is based on the observation of the parasite in smears or aspirates from the lesion. In most cases, abundant amastigotes are observed [11]. The treatment of DL is based on systemic administration of pentavalent antimonials $(20 \mathrm{mg} / \mathrm{kg} /$ day for 20 days $)$, miltefosine $(2-2.5 \mathrm{mg} / \mathrm{kg} /$ day for 28 days $)$ and amphotericin B both deoxycholate $(0.7-1 \mathrm{mg} / \mathrm{kg} /$ day for 30 days) or liposomal (3 mg/kg/day for 10-14 days), although the liposomal form is preferred for the lower toxicity [11]. Therapeutic response may also vary from poor to good, depending on the Leishmania species. Thus, for example, the percentage of cured patients with DL by $L$. (V.) braziliensis treated with 1 course of antimony therapy for 30 days in its highest dosage $(20 \mathrm{mg} / \mathrm{kg} /$ day) is $24 \%$ [7], while in patients with DL by L. (V.) panamensis, the cure rate is $86.3 \%$, as shown here. With liposomal amphotericin use (dose ranging from 17 to $37 \mathrm{mg} / \mathrm{kg}$, used in 7-14 days of treatment), the final cure rate was $65 \%$ [12]. As shown in this work, pentamidine at a dose of $3 \mathrm{mg} / \mathrm{kg} /$ day (4 applications) is also a good option to treat DL even in cases having a high number of lesions.

In endemic areas for leishmaniasis, DL is considered as an opportunistic infection mainly in HIV positive patients in whom therapeutic failures and relapses are frequent [13]. Differential diagnosis of DL include diseases such as psoriasis, histoplasmosis (and other relevant deep mycoses in immunosuppressed patients), pemphigus, pityriasis rosea and lupus [14] but also other cutaneous forms of leishmaniasis such as DCL and post-kala-azar dermal leishmaniasis (PKDL) [15].

DCL was described for the first time in Venezuela by Convit and Lapenta [16] in 1948. This clinical manifestation of DCL is associated with Leishmania species of the Leishmania subgenus, mainly L. (L.) amazonensis (in the New World) and $L$. (L.) aethiopica (in the Old World) $[17,18]$. DCL appears during the first decades of age, with periods of remission and frequent relapses. The lesions are mostly papules and nodules; they do not ulcerate [11]. The Montenegro skin test is predominantly negative, and histologically, granulomas with few lymphocytes and abundant parasites are observed. DCL is more severe because a complete inhibition of specific cellular immunity occurs and the therapeutic response is poor and therefore, relapses occur more frequently $[19,20]$. In DCL, the inhibition of cellular immune response is complete. Contrary to DL, there is no fully effective treatment against DCL. Temporary improvement has been observed in Venezuela using immunotherapy with BCG and heat-dead $L$. (L.) amazonensis promastigotes [21], combined with other drugs such as pentavalent antimonial, amphotericin B and miltefosine. However, relapses of lesions make it necessary to use multiple schemes of treatment [22-24].

In turn, PKDL is caused by L. (L.) donovani in East Africa and India. This disease is characterized by the appearance of rash during weeks or months, followed by macules and plaques especially in the face, upper chest and upper limbs. Sometimes, mucosal involvement may occur. PKDL occurs in patients who previously had visceral leishmaniasis. In In- 
dia, PKDL requires specific treatment, while in African countries, the disease usually heals spontaneously [25].

Although DL has been showing an increase in the number of cases in recent years in countries such as Brazil and Colombia, this is a rare entity and poorly described in the literature. In this clinical manifestation, anergy is not absolute, lesions heal easily and patients show good response to drugs recommended by the WHO to treat LCL such as pentavalent antimonials and miltefosine, and therefore, patients have good prognosis. It is very important to distinguish it from other cutaneous manifestations, mainly from DCL and PKDL, because there are significant differences in etiology, treatment response and prognosis.

\section{Statement of Ethics}

The authors state that the patients gave their informed consent complying with all ethical guidelines for human studies.

\section{Disclosure Statement}

The authors declare no conflicts of interest.

\section{References}

1 Sánchez SL, Saenz AL, Pancorbo MJ, Zegarra R, Garcés VN, Regis-Roggero A: Leishmaniasis. Peruan Dermatol 2004;14:82-98.

2 Turetz ML, Machado PR, Ko AI, Alves F, Bittencourt A, Almeida RP, et al: Disseminated leishmaniasis: a new and emerging form of leishmaniasis observed in northeastern Brazil. J Infect Dis 2002;186:1829-1834.

-3 Sousa AQ, Pompeu MML, Sólon FRN, Frutuoso MS, Teixeira MJ, Silva TMJ: Disseminated cutaneous leishmaniasis: a patient with 749 lesions. Braz J Infect Dis 2006;10:230.

4 Carvalho EM, Barral A, Costa JM, Bittencourt A, Marsden P: Clinical and immunopathological aspects of disseminated cutaneous leishmaniasis. Acta Trop 1994;56:315-325.

-5 Motta ACF, Arruda D, Souza CS, Foss NT: Disseminated mucocutaneous leishmaniasis resulting from chronic use of corticosteroid. Int J Dermatol 2003;42:703-706.

6 Silveira FT, Lainson R, Corbett CEP: Clinical and immunopathological spectrum of American cutaneous leishmaniasis with special reference to the disease in Amazonian Brazil: a review. Mem Inst Oswaldo Cruz 2004;99:239-251.

7 Machado PR, Rosa MEA, Costa D, Mignac M, Silva JS, Schriefer A, et al: Reappraisal of the immunopathogenesis of disseminated leishmaniasis: in situ and systemic immune response. Trans R Soc Trop Med Hyg 2011;105:438-444.

-8 Vieira MGS, Oliveira F, Arruda S, Bittencourt AL, Barbosa AA Jr, Barral-Netto M, et al: B-cell infiltration and frequency of cytokine producing cells differ between localized and disseminated human cutaneous leishmaniases. Mem Inst Oswaldo Cruz 2002;97:979-983.

-9 Sakaguchi S: Naturally arising Foxp3-expressing CD25+CD4+ regulatory T cells in immunological tolerance to self and non-self. Nat Immunol 2005;6:345-352.

10 Shevach EM, DiPaolo RA, Andersson J, Zhao DM, Stephens GL, Thornton AM: The lifestyle of naturally occurring CD4+CD25+Foxp3+ regulatory T cells. Immunol Rev 2006;212:60-73.

11 World Health Organization: Control of the Leishmaniases: Report of a Meeting of the WHO Expert Committee on the Control of Leishmaniases. Technical Report Series, No. 949. Geneva, World Health Organization, 2010.

-12 Machado PR, Rosa ME, Guimarães LH, Prates FV, Queiroz A, Schriefer A, Carvalho EM: Treatment of disseminated leishmaniasis with liposomal amphotericin B. Clin Infect Dis 2015;61:945-949.

13 Guerra JA, Coelho L, Pereira F, Siqueira A, Ribeiro R, Almeida TM, Lacerda MV, Barbosa M, Sinésio T: American tegumentary leishmaniasis and HIV-AIDS association in a tertiary care center in the Brazilian Amazon. Am J Trop Med Hyg 2011;85:524-527. 


\section{Case Reports in Dermatology}

\begin{tabular}{l|l}
\hline Case Rep Dermatol 2015;7:275-286 \\
\hline DOI: $10.1159 / 000441120$ & $\begin{array}{l}\text { (C) 2015 The Author(s). Published by S. Karger AG, Basel } \\
\text { www.karger.com/cde }\end{array}$ \\
\hline
\end{tabular}

Vélez et al.: Disseminated Cutaneous Leishmaniasis in Colombia: Report of 27 Cases

14 Aghaei S, Salmanpour R, Handjani F, Monabati A, Mazharinia N, Dastgheib L: Ulcerated disseminated cutaneous leishmaniasis associated with vitiligo, hypothyroidism, and diabetes mellitus in a patient with Down syndrome. Dermatol Online J 2004;10:21.

15 World Health Organization: The Post Kala Azar Dermal Leishmaniasis Atlas. A Manual for Health Workers. Geneva, World Health Organization, 2012, chapter 1-2.

16 Convit J, Lapenta P: About a case of disseminated cutaneous leishmaniasis (in Spanish). Rev Policlin Caracas 1948;XVII:153-158.

$\checkmark 17$ Mengistu G, Akuffo HO, Yemane-Berhan T, Britton S, Fehniger TE: Serum antibody specificities to Leishmania aethiopica antigens in patients with localized and diffuse cutaneous leishmaniasis. Parasite Immunol 1990;12:495-500.

18 Bryceson AD: Diffuse cutaneous leishmaniasis in Ethiopia. I. The clinical and histological features of the disease. Trans R Soc Trop Med Hyg 1968;63:708-737.

19 Franke ED, Lucas CM, Tovar AA, Hever Kruger J, Seminario de Rivera MV, Wignall FS: Diffuse cutaneous leishmaniasis acquired in Perú. Am J Trop Med Hyg 1990;43:260-262.

20 Zerpa 0, Convit J: Diffuse cutaneous leishmaniasis in Venezuela. Gaz Med Bahia 2009;79:30-34

21 García Bustos MF, Barrio AB, Parodi Ramoneda CM, Ramos F, Mora MC, Convit J, Basombrío MA: Immunological correlates of cure in the first American cutaneous leishmaniasis patient treated by immunotherapy in Argentina. A case report. Invest Clin 2011;52:365-375.

22 González LM, Vélez ID: Miltefosine for disseminated cutaneous leishmaniasis. Biomédica Rev Inst Nac Salud 2006;26:13-16.

23 Zerpa O, Blanco B, Kannee C, Ulrich M, Sindermann H, Engel J, et al: Treatment of diffuse cutaneous leishmaniasis with miltefosine: a case report. Int J Dermatol 2006;45:751-753.

24 Zerpa O, Ulrich M, Blanco B, Polegre M, Ávila A, Matos N, Mendoza I, Pratlong F, Ravel C, Convit J: Diffuse cutaneous leishmaniasis responds to miltefosine but then relapses. Br J Dermatol 2007;156:1328-1335.

25 Guimarães LH, Machado PRL, Lago EL, Morgan DJ, Schriefer A, Bacellar O, Carvalho EM: Atypical manifestations of tegumentary leishmaniasis in a transmission area of Leishmania braziliensis in the state of Bahia, Brazil. Trans R Soc Trop Med Hyg 2009;103:712-715.

Table 1. Parasitological and clinical differences between DL and DCL

\begin{tabular}{|c|c|c|}
\hline Clinical form & DL & DCL \\
\hline Species & L. braziliensis, L. panamensis and L. guayanensis & L. amazonensis and L. aethiopica \\
\hline Clinical signs & Papules, superficial nodules and ulcerations & $\begin{array}{l}\text { Infiltrated papules and nodules, infiltrated } \\
\text { plaques resembling lepromatous leprosy }\end{array}$ \\
\hline Mucosal involvement & Almost half of patients & Absent \\
\hline $\begin{array}{l}\text { Inhibition of cellular } \\
\text { immune response }\end{array}$ & Partial & Total \\
\hline Montenegro skin test & Positive or negative & Negative \\
\hline Histopathology & $\begin{array}{l}\text { Granuloma composed of lymphocytic } \\
\text { infiltrates with very few parasites }\end{array}$ & $\begin{array}{l}\text { Macrophage granuloma with abundant } \\
\text { parasites }\end{array}$ \\
\hline Therapeutic response & Variable* & Poor \\
\hline Recommended treatment & $\begin{array}{l}\text { Pentavalent antimonials, miltefosine and } \\
\text { amphotericin B }\end{array}$ & $\begin{array}{l}\text { Immunotherapy combined with pentavalent } \\
\text { antimonials and/or miltefosine or pentamidine }\end{array}$ \\
\hline
\end{tabular}




\section{Case Reports in \\ Dermatology}

Case Rep Dermatol 2015;7:275-286

\begin{tabular}{l|l}
\hline DOI: 10.1159/000441120 & $\begin{array}{l}\text { C } 2015 \text { The Author(s). Published by S. Karger AG, Basel } \\
\text { www.karger.com/cde }\end{array}$ \\
\hline
\end{tabular}

Vélez et al.: Disseminated Cutaneous Leishmaniasis in Colombia: Report of 27 Cases

Table 2. Demographic and clinical characteristics of patient with DCL

\begin{tabular}{ll}
\hline Patients & 27 \\
Region of origin & \\
$\quad$ Northwest & 25 \\
$\quad$ Center & 1 \\
$\quad$ South & 1 \\
Median age [range], years & $34[4-75]$ \\
Sex, male/female & $23(85) / 4(15)$ \\
Race & \\
$\quad$ Mixed & $20(74)$ \\
$\quad$ Black & $5(18)$ \\
$\quad$ Amerindian & $2(7)$ \\
Baseline comorbidities* & $18(15)$ \\
Range of number of lesions & $12-294$ \\
Nasal mucosal involvement & $7(25)$ \\
Montenegro skin test & \\
$\quad$ Done & 20 \\
$\quad$ Positive/negative & $18 / 3$ \\
$\quad$ Average size [range], mm & $6.8[5-12]$ \\
Leishmania spp. & \\
$\quad$ L. panamensis & $15 / 16$ \\
Treatment & \\
$\quad$ Meglumine antimoniate & 18 \\
$\quad$ Miltefosine & 1 \\
Miltefosine + meglumine antimoniate & 2 \\
$\quad$ Meglumine antimoniate + amphotericin B & \\
$\quad$ Pentamidine & 1 \\
$\quad$ Pentamidine + topical amphotericin B & 2 \\
$\quad$ Amphotericin B + miltefosine & 1 \\
$\quad$ topical amphotericin B & 1 \\
\hline & 1 \\
\hline
\end{tabular}

Figures are n (\%), unless otherwise indicated. * Diabetes mellitus, obesity, HIV/AIDS, leukemia, vitiligo, hypertension. 


\section{Case Reports in Dermatology}

\begin{tabular}{l|l}
\hline Case Rep Dermatol 2015;7:275-286 \\
\hline DOI: $10.1159 / 000441120$ & $\begin{array}{l}\text { C } 2015 \text { The Author(s). Published by S. Karger AG, Basel } \\
\text { www.karger.com/cde }\end{array}$ \\
\hline
\end{tabular}

Table 3. Clinic, demographic and therapeutic characteristic of patients with disseminated cutaneous leishmaniasis

\begin{tabular}{|c|c|c|c|c|c|c|c|c|c|c|}
\hline $\begin{array}{l}\text { Patient } \\
\text { code }\end{array}$ & Provenience & Gender & $\begin{array}{l}\text { Age, } \\
\text { years }\end{array}$ & Race & $\begin{array}{l}\text { Comor- } \\
\text { bidity }\end{array}$ & Lesions & $\begin{array}{l}\text { Mucosal in- } \\
\text { volvement }\end{array}$ & MST & Treatment & Outcome \\
\hline 001 & Choco & Male & 28 & Black & $\mathrm{D}$ & 85 & - & + & $\begin{array}{l}\text { 1st MA (i.m.), 2nd } \\
\text { miltefosine (o) }\end{array}$ & $\begin{array}{l}\text { 1st: failure, } \\
\text { 2nd: cure }\end{array}$ \\
\hline 002 & Antioquia & Male & 61 & Mestizo & $\mathrm{H}, \mathrm{O}$ & 103 & - & - & $\begin{array}{l}\text { Pentamidine (i.m.) } \\
+A m B(t)\end{array}$ & Cure \\
\hline 003 & Tolima & Male & 45 & Mestizo & $\mathrm{H}$ & 56 & + & + & $\begin{array}{l}\text { 1st MA (i.m.), 2nd } \\
\text { AmB (t) }\end{array}$ & $\begin{array}{l}\text { 1st: failure, } \\
\text { 2nd: cure }\end{array}$ \\
\hline 004 & Antioquia & Male & 55 & Mestizo & $\mathrm{H}$ & 17 & - & ND & MA (i.m.) & Cure \\
\hline 005 & Antioquia & Male & 34 & Mestizo & $\begin{array}{l}\text { HIV/AIDS, } \\
\text { TB, KS }\end{array}$ & 200 & + & - & $\begin{array}{l}\text { lAmB (i.v.) + } \\
\text { miltefosine (o) }\end{array}$ & Improvement \\
\hline 006 & Caquetá & Male & 21 & Mestizo & None & 32 & + & ND & MA (i.m.) & Cure \\
\hline 007 & Antioquia & Female & 55 & Mestizo & LKP & 70 & - & + & MA (i.m.) & Cure \\
\hline 008 & Choco & Male & 19 & Mestizo & None & 16 & + & + & MA (i.m.) & Cure \\
\hline 009 & Antioquia & Male & 21 & Black & None & 136 & + & + & MA (i.m.) & Cure \\
\hline 010 & Antioquia & Male & 28 & Mestizo & None & 27 & - & + & MA (i.m.) & Cure \\
\hline 011 & Antioquia & Male & 29 & Mestizo & None & 41 & - & + & MA (i.m.) & Cure \\
\hline 012 & Antioquia & Male & 26 & Black & None & 294 & - & + & Miltefosine (o) & Cure \\
\hline 013 & Antioquia & Male & 22 & Mestizo & None & 13 & - & ND & MA (i.m.) & Cure \\
\hline 014 & Antioquia & Male & 22 & Mestizo & None & 14 & - & + & MA (i.m.) & Cure \\
\hline 015 & Cordoba & Female & 30 & Mestizo & None & 17 & - & ND & MA (i.m.) & Cure \\
\hline 016 & Antioquia & Female & 4 & Mestizo & None & 50 & - & ND & MA (i.m.) & Cure \\
\hline 017 & Antioquia & Male & 23 & Mestizo & None & 12 & - & + & MA (i.m.) & Cure \\
\hline 018 & Antioquia & Male & 22 & Mestizo & None & 13 & - & ND & MA (i.m) & Cure \\
\hline 019 & Antioquia & Male & 41 & Mestizo & V & 12 & - & ND & MA (i.m.) & Cure \\
\hline 020 & Choco & Male & 27 & Mestizo & $\mathrm{A}$ & 17 & - & + & MA (i.m.) & Cure \\
\hline 021 & Antioquia & Male & 43 & Indian & Dy & 50 & - & + & Pentamidine (i.m.) & Cure \\
\hline 022 & Antioquia & Male & 32 & Mestizo & None & 46 & - & + & MA (i.m.) & Cure \\
\hline 023 & Choco & Male & 12 & Indian & LKM & 21 & - & + & MA (i.m.) & Cure \\
\hline 024 & Antioquia & Female & 55 & Mestizo & $\mathrm{E}$ & 17 & - & + & MA (i.m.) & Cure \\
\hline 025 & Antioquia & Male & 46 & Mestizo & None & 46 & + & + & MA (i.m) & Cure \\
\hline 026 & Choco & Male & 44 & Black & None & 250 & - & + & $\begin{array}{l}\text { 1st MA (i.m.), 2nd } \\
\text { miltefosine (o) }\end{array}$ & $\begin{array}{l}\text { 1st: failure, } \\
\text { 2nd: cure }\end{array}$ \\
\hline 027 & Antioquia & Male & 75 & Black & $\mathrm{H}, \mathrm{CKD}$ & 143 & + & + & Pentamidine (i.m.) & Cure \\
\hline
\end{tabular}

$\mathrm{D}=$ Diabetes; $\mathrm{H}$ = hypertension; $\mathrm{O}=$ obesity; $\mathrm{TB}$ = tuberculosis; $\mathrm{KS}$ = Kaposi's sarcoma; $\mathrm{LKP}=$ leukopenia; $\mathrm{V}=$ vitiligo; $\mathrm{A}=$ anorexia; Dy = dyslipidemia; LKM = leukemia; $\mathrm{E}=$ epilepsy; $\mathrm{CKD}=$ chronic kidney disease; $\mathrm{MST}=$ Montenegro skin test; $\mathrm{ND}=$ not done; $\mathrm{MA}=$ meglumine antimoniate; $\mathrm{AmB}=$ amphotericin $\mathrm{B} ; \mathrm{IAmB}=$ liposomal amphotericin $\mathrm{B} ;$ i.m. = intramuscular; i.v. = intravenous; $\mathrm{o}=$ oral; $\mathrm{t}=$ topical. 


\section{Case Reports in Dermatology}

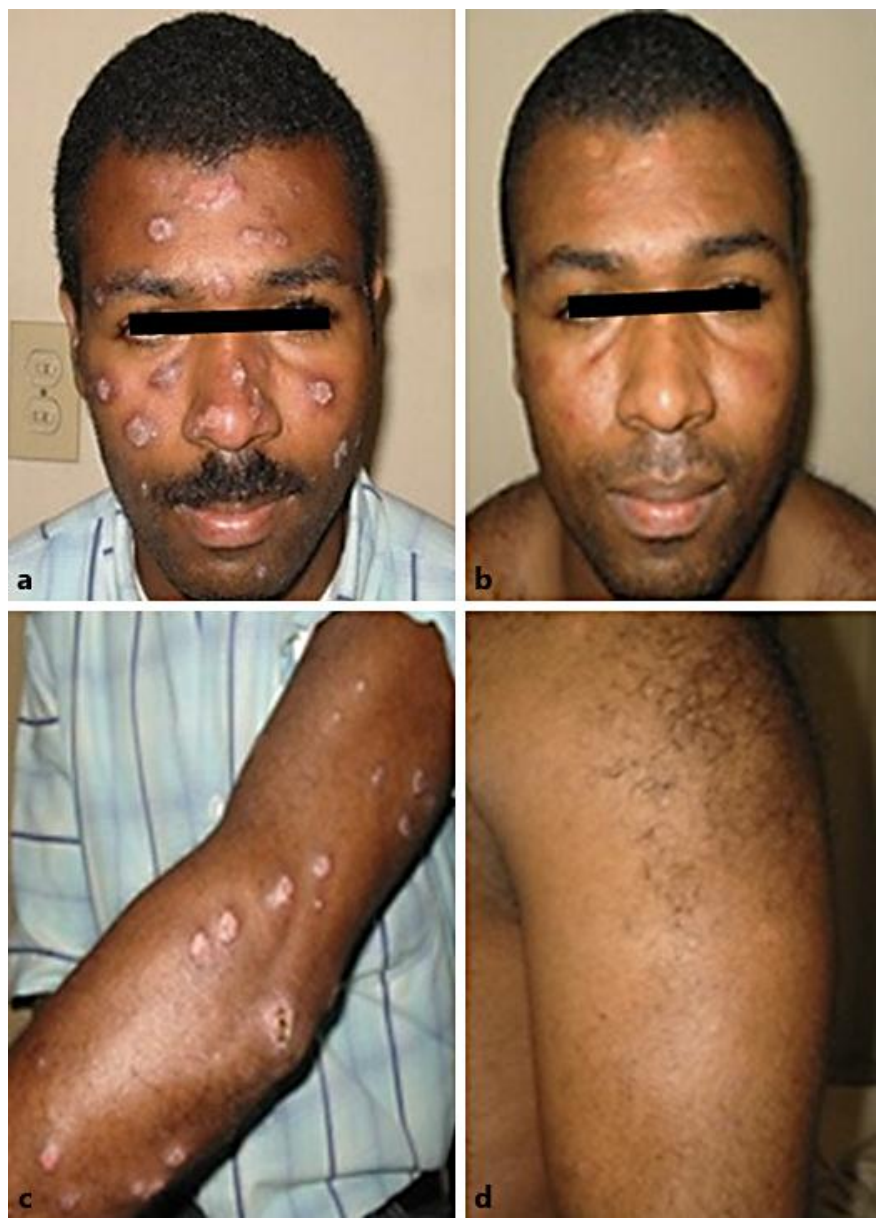

Fig. 1. Male with 294 lesions with good response to treatment with miltefosine. Previously, the patient had failed to respond to amphotericin B plus one scheme of intramuscular meglumine antimoniate treatment showing toxicity and worsening clinical disease with new lesions. Lesions before $(\mathbf{a}, \mathbf{c})$ and after treatment (b, d). 

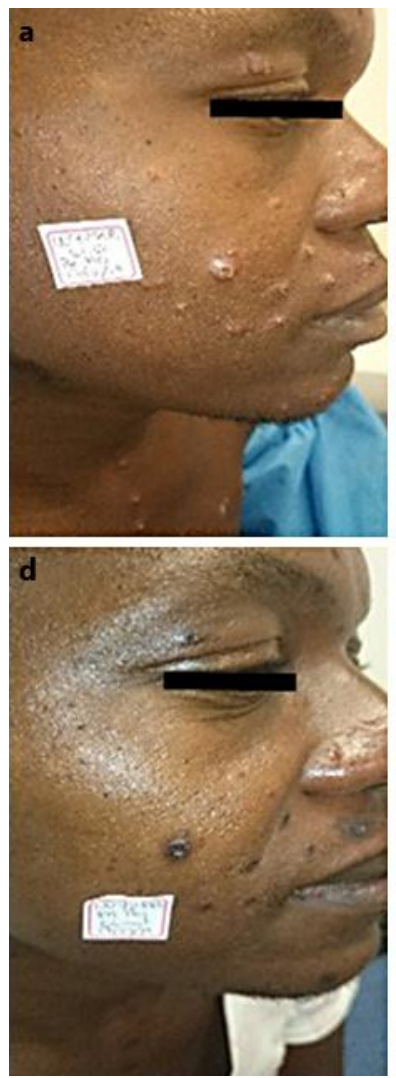

b
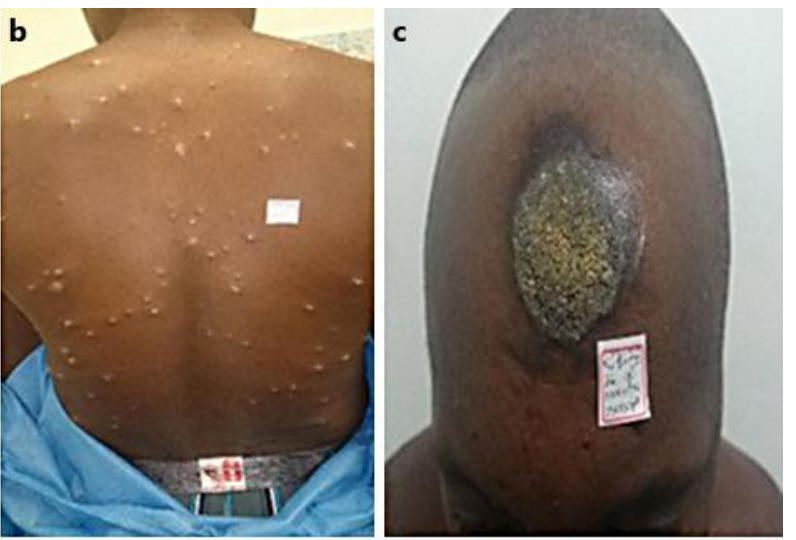

e

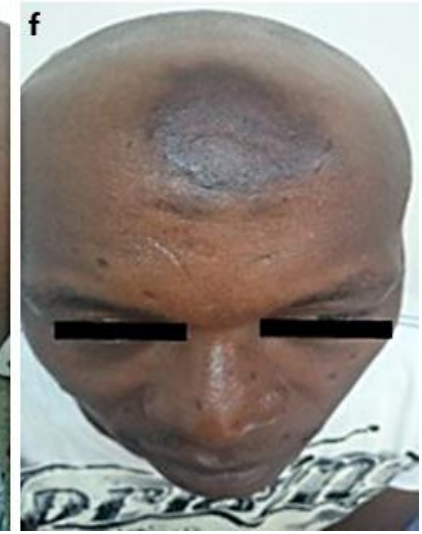

Fig. 2. Male with 250 lesions. This patient was treated with intramuscular meglumine antimoniate. After failure, the patient was treated with miltefosine and was cured. Lesions before (a-c) and after treatment (d-f). 


\section{Case Reports in Dermatology}

Vélez et al.: Disseminated Cutaneous Leishmaniasis in Colombia: Report of 27 Cases

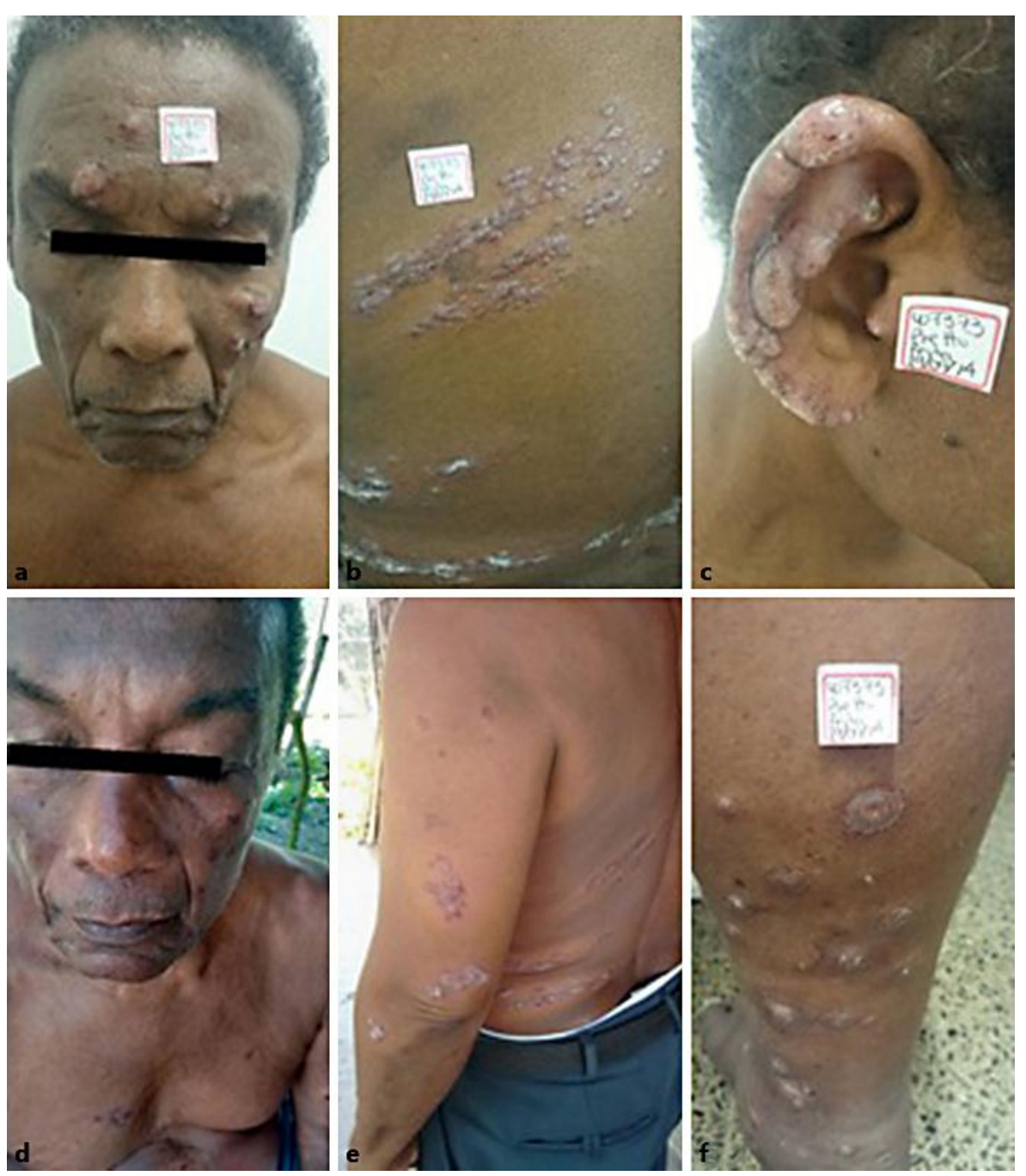

Fig. 3. Patient with 143 lesions and mucosal involvement, who had previously received systemic management with glucantime and miltefosine. He presented renal toxicity and reactivation and was treated with pentamidine. He had complete resolution of lesions without systemic toxicities. Lesions before (a-c, f) and after treatment (d, e). 

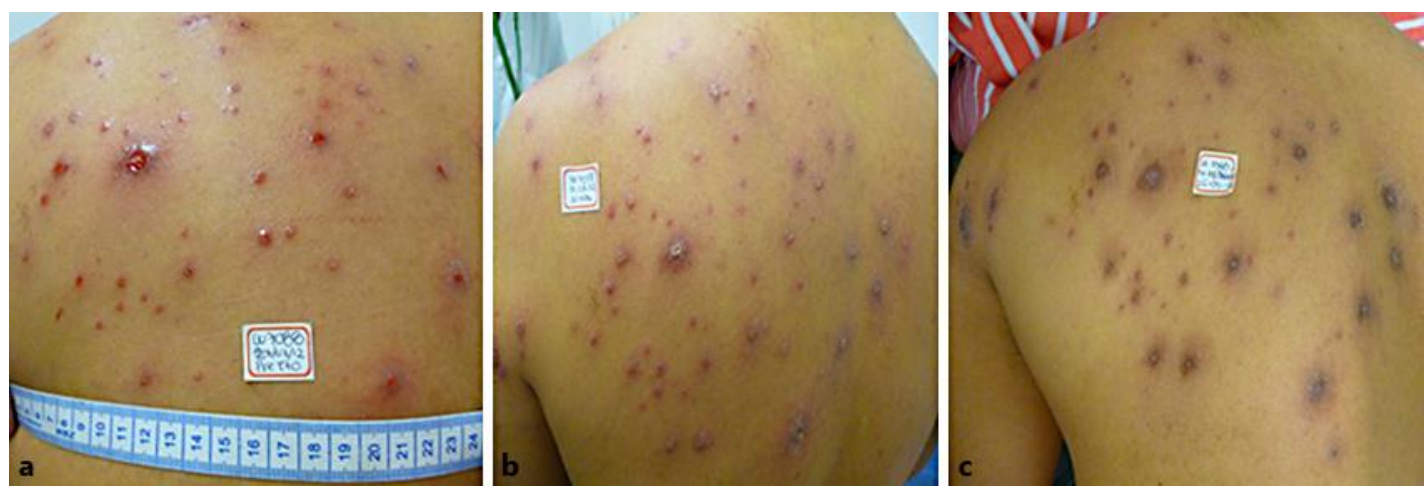

Fig. 4. Patient with 56 lesions who showed good response to treatment with topical amphotericin B. 